(2) Open Access Full Text Article

ORIGINAL RESEARCH

\title{
Loganin Attenuates Septic Acute Renal Injury with the Participation of AKT and Nrf2/HO-I Signaling Pathways
}

This article was published in the following Dove Press journal:

Drug Design, Development and Therapy

\author{
Jin Zhang' \\ Changsong Wang ${ }^{2}$ \\ Kai Kang' \\ Haitao Liu ${ }^{2}$ \\ Xiaowei Liu' \\ Xiaonan Jia' \\ Kaijiang $\mathrm{Yu}^{\prime}$ \\ 'Department of Critical Care Medicine, \\ The First Affiliated Hospital of Harbin \\ Medical University, Harbin Medical \\ University, Harbin, Heilongjiang I5000I, \\ People's Republic of China; ${ }^{2}$ Department \\ of Critical Care Medicine, Harbin Medical \\ University Cancer Hospital, Harbin \\ Medical University, Harbin, Heilongjiang \\ I5008I, People's Republic of China
}

Purpose: Sepsis, a destructive inflammatory response syndrome, is the principal reason to induce death in the intensive care unit. Loganin has been proved to possess the property of anti-inflammation, antioxidant, neuroprotection, and sedation. The primary aim of this study was to evaluate whether Loganin could alleviate acute kidney injury (AKI) during sepsis and investigate the latent mechanisms.

Methods: Septic AKI models were established by cecal ligation and puncture (CLP) surgery in mice and given Loganin $(20,40,80 \mathrm{mg} / \mathrm{kg}$ ) by gavage. Lipopolysaccharides (LPS)stimulated human kidney proximal tubular (HK2) cells incubated in Loganin $(5,10,20 \mu$ $\mathrm{M})$ were used to explore the accurate mechanisms. Survival rate, renal function (creatinine and blood urea nitrogen), and renal pathological changes were detected in septic mice. Oxidative stress markers (SOD, GSH-Px, MDA, and SOD), mitochondrial membrane potential, mitochondrial calcium overload, and nuclear factor E2-related factor 2 (Nrf2)/hemeoxygenase 1 (HO-1) pathway activation in vivo and in vitro were determined by commercial kits and Western blot. Cell apoptosis, apoptotic-related protein (cleaved caspase-3, Bcl-2, and Bax) expression and protein kinase B (AKT) phosphorylation in vivo and in vitro were measured by TUNEL staining and Western blot. Finally, AKT blockage by $10 \mu \mathrm{M}$ LY294002 or Nrf2 inhibition by10 $\mu$ M ML385 were utilized to prove the involvement of AKT and Nrf2/HO-1 pathway in AKI during sepsis.

Results: We found Loganin treatment $(20,40,80 \mathrm{mg} / \mathrm{kg})$ mitigated septic AKI reflected by elevated renal function and palliative pathological changes. Oxidative stress and apoptosis in the kidney and LPS-treated HK2 cells were also inhibited by Loganin administration, which was accompanied by AKT and Nrf2/HO-1 pathway activation. Besides, the protective effects of Loganin could be diminished by AKT or Nrf2 blockage, indicating the involvement of AKT and Nrf2/HO-1 pathway.

Conclusion: The results suggested that the protective effects of Loganin on AKI during sepsis might be mediated by AKT and Nrf2/HO-1 pathway signaling activation in kidney proximal tubular cells.

Keywords: sepsis, acute kidney injury, Loganin, AKT, Nrf2/HO-1

\section{Introduction}

Sepsis, a destructive inflammatory response syndrome in clinical practice, is principally caused by multi-factors, such as toxins, pathogenic bacteria, and their metabolic products entering in the blood stream. ${ }^{1,2}$ As a terrible generalized hyperinflammatory condition, sepsis patients suffer a variety of tissue injuries and organ dysfunctions involving in lung, kidney, and heart. ${ }^{3-5}$ Despite many efforts
Department of Critical Care Medicine,

The First Affiliated Hospital of Harbin

Medical University, Harbin Medical

University, 23 Youzheng Street, Harbin,

Heilongjiang 15000I, People's Republic of

China

Tel +86-45I-53643849

Email Yu_kaijiang@126.com
Drug Design, Development and Therapy 2021:15 50I-5/3

501

DovePress

f

in $\mathbf{D}$

\section{(c)}

(c) (1) (5) 202I zhang et al. This work is published and licensed by Dove Medical Press Limited. The full terms of this license are available at https://www.dovepress.com/terms. work you hereby accept the Terms. Non-commercial uses of the work are permitted without any further permission from Dove Medical Press Limited, provided the work is properly attributed. For permission for commercial use of this work, please see paragraphs 4.2 and 5 of our Terms (https://www.dovepress.com/terms.php). 
have been made to reduce mortality and improve the cure rate of sepsis worldwide, sepsis remains a terrible disease that seriously threatens the patients. Only 30\% septic patients survive according to statistics, besides, at least 6 million patients die from septic infection annually according to the statistics of the World Health Organization (WHO). ${ }^{6,7}$ Among the complications of sepsis, acute kidney injury (AKI) is the most common and serious with high mortality. It is considered that over $60 \%$ septic cases occur with AKI and approximately 50\% AKI cases are associated with sepsis. ${ }^{8,9}$ Dreadfully, although the standard treatments are used, the mortality of severe AKI is as high as 45 to $70 \% .{ }^{10}$ Hence, it is extremely urgent to study the accurate mechanisms and develop effective methods to alleviate sepsis-related AKI.

Several studies have revealed the mechanisms related to AKI are controversial, uncontrolled inflammatory response, severe oxidative stress, maladaptive apoptosis, and aberrant endoplasmic reticulum stress are all involved in the pathological process of AKI. ${ }^{11}$ As known, except for inflammation, oxidative stress is frequently prescribed for AKI pathogenesis. Oxidative stress referring to a state of imbalance between oxidation and anti-oxidation is a negative effect produced by free radicals, which is considered to be an important factor leading to multiple diseases, including retinopathy. ${ }^{12}$ Under various pathologic conditions, the strong correlation between oxidative stress injury and nuclear factor E2-related factor $2(\mathrm{Nrf} 2)$ has been previously proved. ${ }^{13-15}$ The preceding study has pointed out that Nrf2/HO-1 pathway is one of the most recognized signaling closely associated with oxidative and anti-oxidative balance. ${ }^{16,17}$ Under normal circumstances, the cap " $n$ " collar subfamily of basic region-leucine zipper transcription factor Nrf2 is restricted in the cytoplasm by binding to its ligand Kelch-like ECH associating protein 1 (Keap1). ${ }^{18}$ Once exposed to oxidative stress stimulation, Nrf2-Keap1 complexes can be dissociated, the detached $\mathrm{Nrf} 2$ translocates into the nucleus to promote hemeoxygenase 1 (HO-1) expression, which involves in the balance of molecules associated with oxidative stress, such as superoxide dismutase (SOD), malonaldehyde (MDA), reactive oxygen species (ROS), and glutathione peroxidase (GSH-Px). ${ }^{19,20}$ Previously, regulating Nrf2 and its downstream genes could decrease inflammatory factor release, reduce oxidative stress, and maintain antiapoptotic and survival abilities in the injured kidney. ${ }^{21}$ Therefore, restraining oxidative stress through activating
Nrf2 pathway might be a possible therapeutic strategy targeting sepsis-related AKI.

The evolving evidence indicates that ROS accumulation resulting from abnormal oxidative stress promotes macromolecule peroxidation, and thereby causing cytochrome c-mediated mitochondrial apoptosis. ${ }^{22}$ Oxidativestress-related excessive ROS generation contributes to cardiolipin oxidation, and thereby resulting in cytochrome c binding reduction. ${ }^{23}$ The free cytochrome $\mathrm{c}$ in the mitochondria migrates from inter-membrane side to the cytoplasm and touches off apoptotic cascade at the molecular level. ${ }^{24}$ Therefore, reducing oxidative stress and thus mitochondrial apoptosis induced by oxidative stress may be a potential therapeutic strategy for septic AKI.

Loganin (iridoid glycoside) is the main active ingredient of Corni fructus, which is the fruit of Cornus officinalis Sieb. and has been used to nourish the liver and kidney in the East for fairly long time. ${ }^{25}$ Loganin has been reported to possess the property of anti-inflammation, antioxidant, anti-diabetes, neuroprotection, and sedation. ${ }^{26-30}$ Liu et al reported that Loganin alleviated diabetic nephropathy by down-regulating MDA level while up-regulating SOD activity in serum and kidney tissues, indicating the antioxidant capacity of Loganin in renal injury models. ${ }^{29}$ Moreover, Loganin could also play a hepatoprotective role in type 2 diabetic $\mathrm{db} / \mathrm{db}$ mice by suppressing inflammatory reaction, oxidative stress, and apoptosis, which are the pathogenesis of septic AKI. ${ }^{28}$ However, whether Loganin can serve as a potential treatment for septic AKI is still unknown. Hence, the following study was conducted to investigate the effects of Loganin on septic AKI and preliminarily explore the related mechanism.

\section{Materials and Methods}

\section{Animals and Surgical Procedure}

Cecal ligation and puncture (CLP) method was used to induce sepsis in mice. Male C57BL/6 mice at the age of 8 weeks (License number: SCXK (Liaoning, China) 2015-0001) were obtained from Changsheng biotechnology Co., Ltd. and kept in a standard laboratory environment (12-hour day/night cycle, $45-55 \%$ humidity, $22 \pm$ $1{ }^{\circ} \mathrm{C}$ ). After the adaption, the mice were randomly divided into the following five groups: I Sham; II CLP; III CLP+L-Loganin (20 $\mathrm{mg} / \mathrm{kg}) ; \quad$ IV CLP +M-Loganin $(40 \mathrm{mg} / \mathrm{kg}) ; \mathrm{V}$ CLP+H-Loganin $(80 \mathrm{mg} /$ $\mathrm{kg}$ ). After anesthesia, the abdomen of mice was open to expose the cecum. The cecal puncture point was the 
midpoint between the end of the cecum and the ligation point. For the mice in sham group, the cecum was found and returned into the abdominal. After the CLP operation, the mice were given Loganin $(20,40,80 \mathrm{mg} / \mathrm{kg})$ or equal volume of vehicle by gavage for once. A part of the mice were euthanized under deep anesthesia 24 $\mathrm{h}$ after the CLP operation to collect serum and renal cortex for follow-up experiments. The remaining mice were used to calculate the survival rate. All the animal treatment was performed in accordance with the Guide for Care and Use of Laboratory Animals (Eighth Edition) published by the Institute of Laboratory Animal Resources Commission on Life Sciences. All laboratory procedures were approved by The First Affiliated Hospital of Harbin Medical University (No. SYDW2019-229).

\section{Creatinine and Blood Urea Nitrogen Analysis}

The collected serum was used to determine the levels of creatinine and blood urea nitrogen in accordance with the manufacturer's instruction (Jiancheng Bioengineering Institute, China).

\section{Histopathological Analysis}

The fixed kidney tissues were embedded in paraffin, sliced into sections at $5 \mathrm{~mm}$ thick, subjected to hematoxylin solution (Solarbio, China), and counterstained with eosin (Sangon, China) in accordance with the manufacturer's instruction. The kidney pathological alterations were observed under light microscopy at 200 $\mathrm{X}$ magnification and scored to evaluate the degree of renal injury.

\section{Immunohistochemical Analysis}

Simply, the above-mentioned kidney sections were blocked in goat serum at room temperature for $15 \mathrm{~min}$, incubated in the primary antibody (Rabbit anti-neutrophil gelatinaseassociated lipocalin (NGAL), dilution: 1:50, Affinity, China) at $4^{\circ} \mathrm{C}$ overnight, and treated with HRP IgG antibody (dilution: 1:500, Thermo Fisher, USA) at room temperature for $1 \mathrm{hTo}$ visualize renal NGAL expression, diaminobenzidine slide (Solarbio, China) and hematoxylin (Solarbio, China) were applied according to the manufacturer's instruction. Finally, the expression of target protein was observed under light microscopy at $400 \mathrm{X}$ magnification.

\section{TUNEL Staining}

Briefly, cell apoptosis in the aforementioned kidney section was detected by TUNEL assay by using the In Situ Cell Death Detection Kit (Roche, Switzerland). After all the procedure required by the manufacturer's instruction, apoptosis was observed under light microscopy at $400 \mathrm{X}$ magnification.

\section{Cell Culture}

Human kidney proximal tubular (HK2) cells were obtained from Procell Life Science \& Technology Co., Ltd. (Wuhan, China) and cultured in DMEM medium (Gibco, USA) in a humidified $5 \% \mathrm{CO}_{2}$ incubator at $37^{\circ}$ C. After adhering to the plates, HK2 cells were exposed to $100 \mathrm{ng} / \mathrm{mL}$ lipopolysaccharides (LPS) with or without Loganin $(5,10,20 \mu \mathrm{M})$ for $48 \mathrm{~h}$. The treated HK2 cells were collected for the future experiments.

\section{AKT or Nrf2 Blockage}

To inhibit the function of AKT or Nrf2, HK2 cells were grown in $10 \mu \mathrm{M}$ LY294002 (a broad-spectrum inhibitor of PI3K) or $10 \mu \mathrm{M}$ ML385 (a specific Nrf2 inhibitor) for 48 $\mathrm{h}$ in the presence of $100 \mathrm{ng} / \mathrm{mL}$ LPS and $20 \mu \mathrm{M}$ Loganin.

\section{Oxidative Stress Marker Analysis}

Oxidative stress markers, including SOD and GSH-Px activity as well as MDA production in the kidney tissues or HK2 cells, were, respectively, measured by corresponding assay kits (Nanjing Jiancheng Biological Engineering Institute, China). The microplate reader (BioTek, USA) was used to read the optical density (OD) value at $570 \mathrm{~nm}$. ROS production in the kidney tissues or HK2 cells was measured by a ROS assay kit (Nanjing Jiancheng Biological Engineering Institute, China) and flow cytometry (NovoCyte, Aceabio, USA) was used for its quantitative analysis.

\section{JC-I Analysis}

Mitochondrial membrane potential detection kit obtained from Beyotime Institute of Biotechnology (Shanghai, China) was used to detect the changes in mitochondrial membrane potential of kidney tissue homogenates or HK2 cells. All the procedures were according to the manufacturer's instructions and flow cytometry (NovoCyte, Aceabio, USA) was used for the quantitative analysis.

\section{Calcium Analysis}

Fluo-4 AM fluorescent probe was used to detect intracellular calcium mobilization. Briefly, kidney tissue 
homogenates or HK2 cells were incubated in $4 \mu \mathrm{M}$ Fluo-4 AM (Beyotime Institute of Biotechnology, China) at $37^{\circ} \mathrm{C}$ for $30 \mathrm{~min}$. After washing by PBS for three times, flow cytometry (NovoCyte, Aceabio, USA) was used for quantitative analysis.

\section{Western Blotting}

Kidney tissues and treated HK2 cells were used to extract total, cytoplasmic, or nuclear protein, and the protein concentration was quantified by the BCA kit (Solarbio, China). The isolated protein was separated by sodium dodecyl sulfate polyacrylamide gel (SDS-PAGE), transferred onto polyvinylidene difluoride (PVDF) membranes and blocked by 5\% skimmed milk. Next, the PVDF membranes were subjected to the primary antibodies and horseradish peroxidase (HRP) labelled secondary antibody. Finally, chemiluminescence (ECL) kit was used to visualize the protein, which integrated intensity was calculated by Gel-Pro-Analyzer. The protein levels were presented as relative expression, which was calculated by comparing with the sham or control group. The primary antibodies were as follows: Rabbit anti-cytochrome c; anti-Bax; antiBcl-2; anti-AKT, anti-p-AKT (Ser473); anti-Nrf2; anti-HO -1 (dilution: 1:1000, Abclonal, China); anti-cleaved caspase-3 (dilution: 1:1000, Affinity, China).

\section{Statistical Analysis}

Data were represented as means \pm standard derivations (SD). The data from three or more groups were analyzed by one-way ANOVA followed by Tukey's multiple comparison tests. $\mathrm{P}$ value less than 0.05 was considered statistically significant.

\section{Results}

\section{Effects of Loganin on the Survival Rate,} Renal Function and Renal Pathological

\section{Changes in Septic Mice}

First of all, we detected the survival rate in septic mice with Loganin administration. As shown in Figure 1A, the survival rate was observably elevated in the Loganintreated septic mice when compared with the model ones $(20,40,80 \mathrm{mg} / \mathrm{kg})$. The concentrations of serum creatinine and blood urea nitrogen (Figure $1 \mathrm{~B}$ and $\mathrm{C}$ ) as well as the expressions of acute kidney injury marker NGAL (Figure 1E) were down-regulated with Loganin treatment $(20,40,80 \mathrm{mg} / \mathrm{kg}, \mathrm{p}<0.05)$. Besides, compared with the septic group, the renal injury score calculated by $\mathrm{HE}$ staining was also decreased with Loganin treatment (20, $40,80 \mathrm{mg} / \mathrm{kg}$, Figure $1 \mathrm{D}$ and $\mathrm{F}, \mathrm{p}<0.05)$. The above results indicated that Loganin not only possessed the feature of down-regulating mortality but also could relieve AKI in septic mice.

\section{Effects of Loganin on Oxidative Stress and Mitochondrial Function in Kidney Tissue of Septic Mice}

Since oxidative stress is considered to be one of the principal elements mediating AKI, we measured the changes in oxidative stress status of kidney tissues after Loganin treatment. As exhibited in Figure 2A-D, the activities of SOD and GSH-Px were up-regulated, while the productions of MDA and ROS were down-regulated in the kidney tissue of septic mice after Loganin treatment $(20,40,80 \mathrm{mg} / \mathrm{kg}, \mathrm{p}<0.05)$, indicating Loganin prevented oxidative stress damage. To investigate whether Loganin was involved in mitochondrial dysfunction associated with renal impairment, we detected mitochondrial function in the kidney tissue of septic mice after Loganin treatment. As described in Figure 2E and F, the mitochondrial membrane potential loss and calcium overload were obvious in the kidney tissues after CLP procedure, which could be remitted by Loganin treatment $(20,40,80 \mathrm{mg} / \mathrm{kg}, \mathrm{p}<0.05)$. With the restoration of mitochondrial function after Loganin treatment, the release of cytochrome c from mitochondria to cytoplasm was also decreased $(20,40,80 \mathrm{mg} / \mathrm{kg}$, Figure $2 \mathrm{G}$ and $\mathrm{H}, \mathrm{p}<0.05)$. Afterwards, the possible molecular mechanism related oxidative stress status was preliminarily studied. As shown in Figure 2I-K, the nuclear translocation of Nrf2 was accelerated in Loganin-treated group $(20,40,80 \mathrm{mg} / \mathrm{kg}, \mathrm{p}<$ 0.05). Accompanied by Nrf2 nuclear translocation, HO-1 expression was also increased in kidney tissue of septic mice $(20,40,80 \mathrm{mg} / \mathrm{kg}, \mathrm{p}<0.05)$. The above results indicated that Loganin reduced oxidative stress injury and promoted mitochondrial function recovery in kidney tissue of septic mice, which might be regulated by Nfr2/HO-1 signaling pathway.

\section{Effects of Loganin on Apoptosis in Kidney Tissue of Septic Mice}

Subsequently, apoptosis in kidney tissues was also studied in our work. As suggested by TUNEL staining of the kidney tissue, apoptosis was distinctly increased after CLP procedure, which could be inhibited by Loganin administration (Figure 3A, 20, 40, $80 \mathrm{mg} / \mathrm{kg}$ ). Consistent with TUNEL staining results, the levels of cleaved caspase- 3 and Bax were decreased, whereas Bcl-2 levels were increased in the kidney 

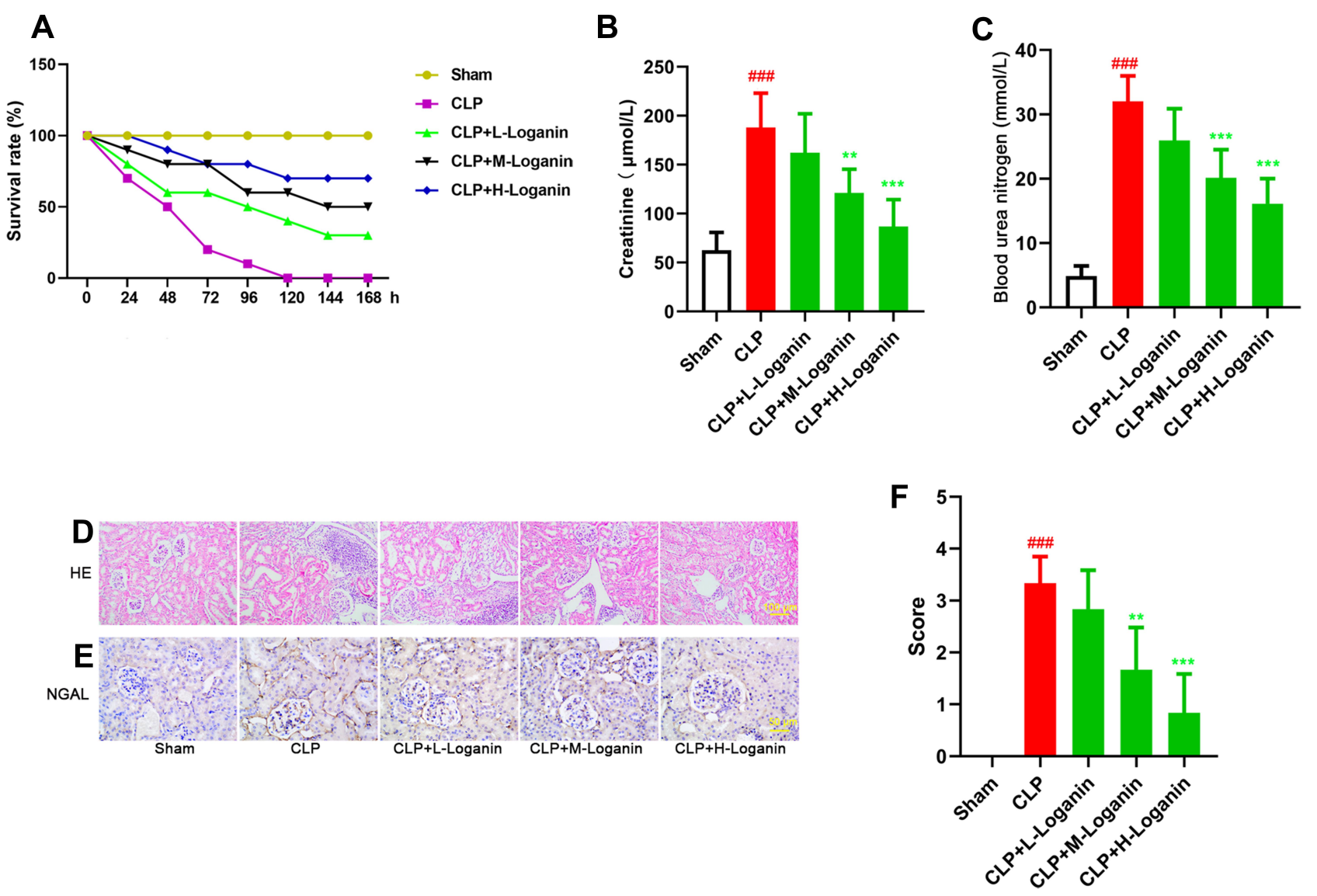

Figure I Effects of Loganin on the survival rate, renal function and renal pathological changes in septic mice. (A) The survival rate in septic mice after Loganin treatment. The levels of serum (B) creatinine and (C) blood urea nitrogen in septic mice after Loganin treatment. (D) HE staining (at 200×magnification) and (E) immunohistochemistry targeting NGAL (at 400xmagnification) in kidney tissue of septic mice after Loganin treatment. (F) HE staining score. Data were represented as mean \pm SD at least six independent experiments and analyzed by one-way analysis of variance (ANOVA) followed by Tukey's multiple comparison test. ${ }^{\ldots} \mathrm{p}<0.001$ vs the sham group and ** $<$ 0.01 , $* * * \mathrm{p}<0.001$ vs the CLP group.

of septic mice treated with Loganin (Figure 3B-D, 20, 40, $80 \mathrm{mg} / \mathrm{kg}, \mathrm{p}<0.05$ ). Simultaneously, AKT phosphorylation was down-regulated by CLP procedure compared with the sham operation, which was restored by Loganin administration (Figure 3E, 20, 40, $80 \mathrm{mg} / \mathrm{kg}, \mathrm{p}<0.05$ ). The above results indicated that Loganin inhibited apoptosis in kidney tissue of septic mice, which might be regulated by AKT signaling pathway.

\section{Effects of Loganin on Oxidative Stress and Mitochondrial Function in LPS-Treated HK2 Cells}

Since the in vivo experiments suggested Loganin could alleviate oxidative stress injury and promoted mitochondrial function recovery in septic kidney tissues, we should prove the beneficial effects of Loganin in vitro. As described in Figure 4A-D, SOD and GSH-Px activities were decreased, while MDA and ROS productions were increased in LPS-incubated HK2 cells $(\mathrm{p}<0.05)$. The incubation of Loganin could eliminate this phenomenon $(5,10,20 \mu \mathrm{M}, \mathrm{p}<0.05)$. In addition, the loss of mitochondrial membrane potential and the overload of calcium, accompanied by cytochrome c release to cytoplasm, were almost reversed by Loganin incubation (Figure 4E-J, 5, $10,20 \mu \mathrm{M}, \mathrm{p}<0.05)$. Similar to the in vivo results, the abnormal activation of Nrf2/HO-1 signaling pathway was also reversed with Loganin treatment (Figure 4K-M, 20 $\mu \mathrm{M}, \mathrm{p}<0.05$ ), indicating Loganin mitigated oxidative stress and facilitated mitochondrial function recovery possibly via activating Nrf2/HO-1 signaling pathway in LPSstimulated HK2 cells.

\section{Effects of Loganin on Apoptosis in LPS-Treated HK2 Cells}

As shown in Figure 5A, the apoptosis rate of LPStreated HK2 cells was distinctly increased compared 

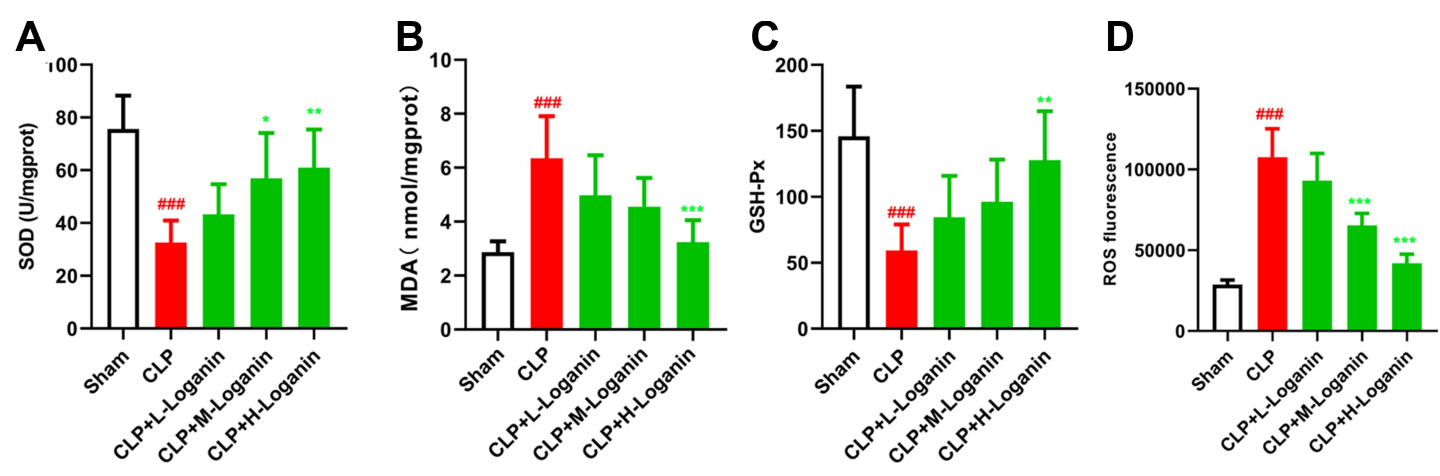

\section{$\mathbf{E}$}
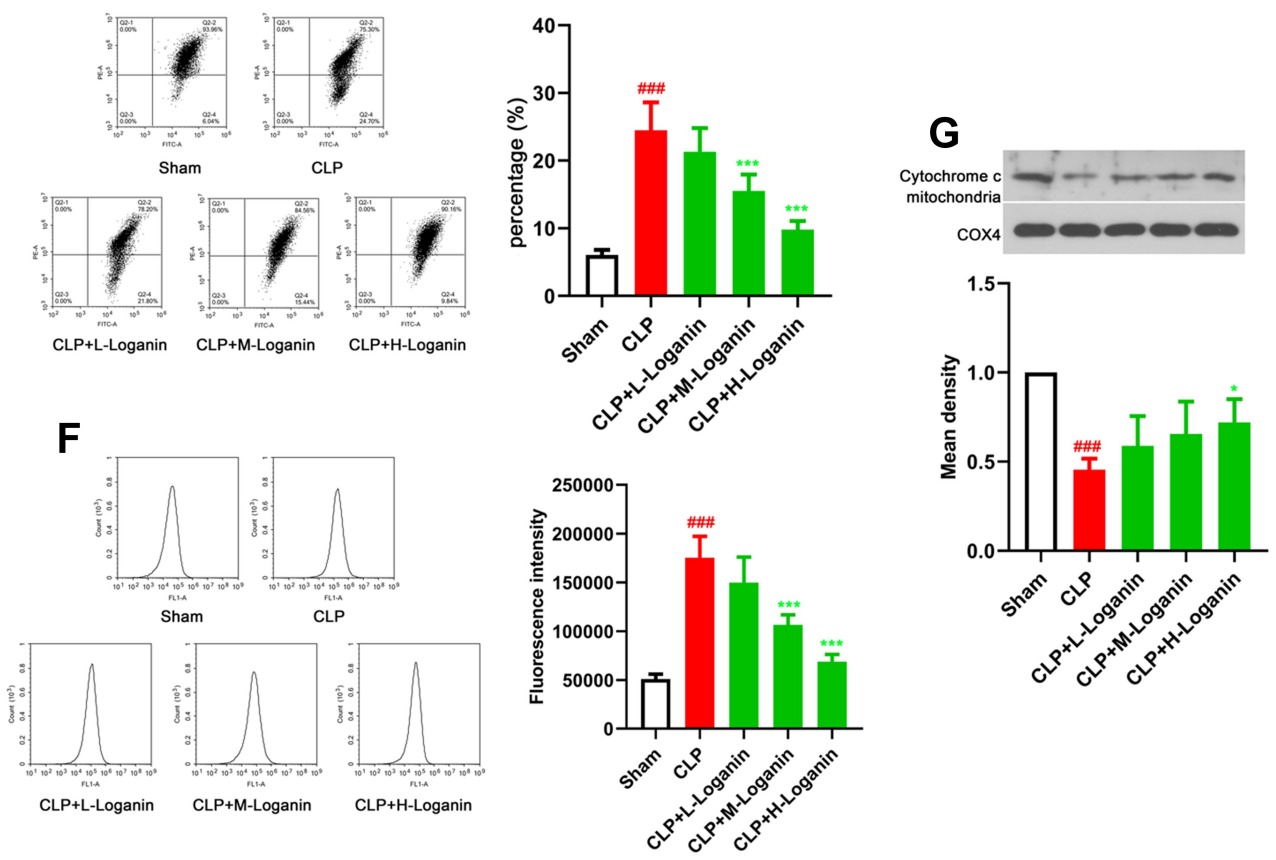

\section{H} Cytochrome c $\rightarrow-\infty=-\infty$ GAPDH $-\infty-\infty$
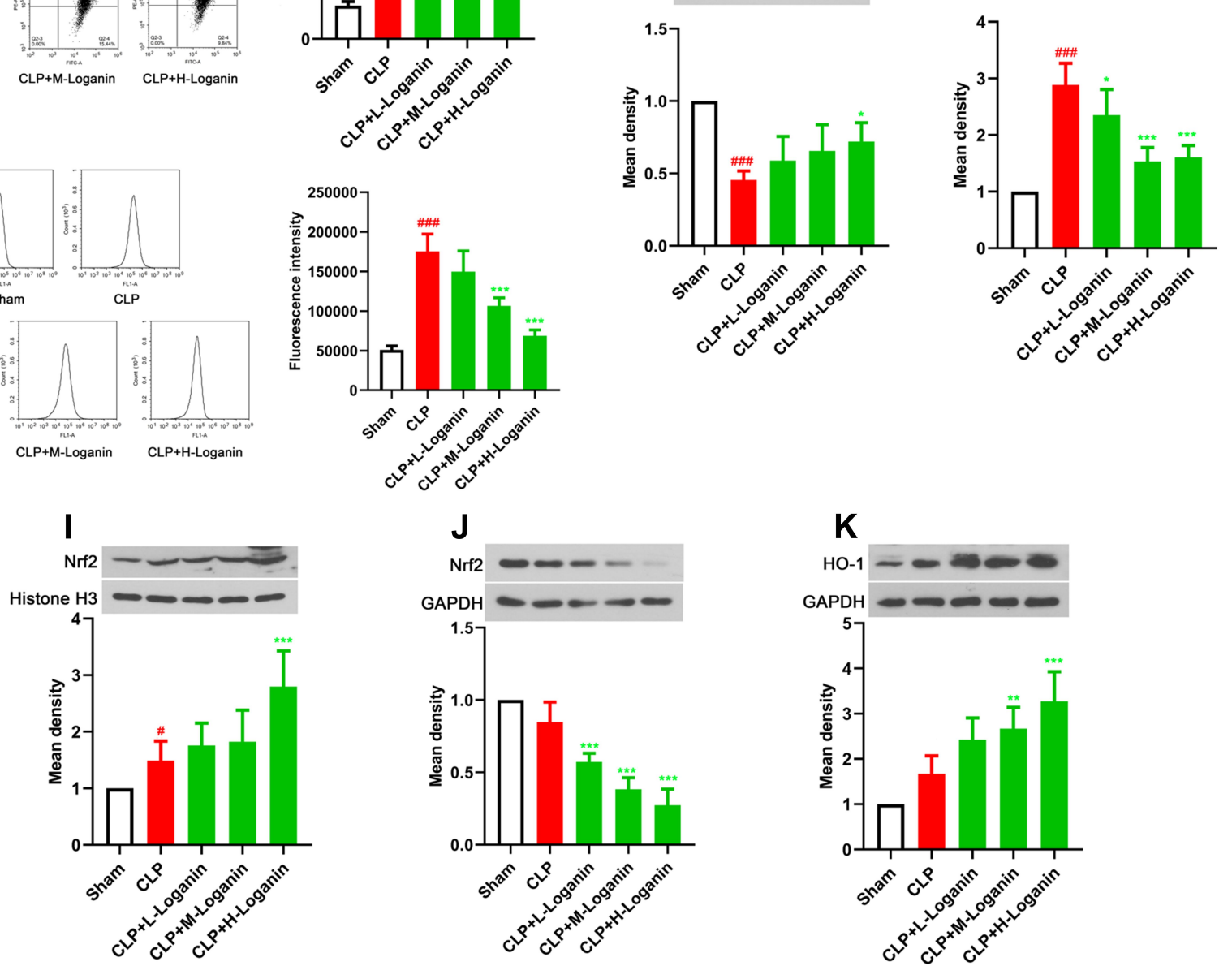

Figure 2 Effects of Loganin on oxidative stress and mitochondrial function in kidney tissue of septic mice. (A) SOD activity in kidney tissue of septic mice after Loganin treatment. (B) MDA levels in kidney tissue of septic mice after Loganin treatment. (C) GSH-Px activity in kidney tissue of septic mice after Loganin treatment. (D) ROS production in kidney tissue of septic mice after Loganin treatment. (E) Flow cytometry was used to analyze JC-I staining in kidney tissue of septic mice after Loganin treatment. (F) Flow cytometry was used to analyze calcium overload in kidney tissue of septic mice after Loganin treatment. Representative Western blot for (G) mitochondrial cytochrome c, (H) cytoplasmic cytochrome c (I) nuclear Nrf2, (J) cytoplasmic Nrf2 and (K) HO-I in kidney tissues of septic mice after Loganin treatment. Data were represented as mean \pm SD at least six independent experiments and analyzed by one-way analysis of variance (ANOVA) followed by Tukey's multiple comparison test. ${ }^{\#}<0.05,{ }^{\# \#}<0.001$ vs the sham group and ${ }^{*} p<0.05 * * p<0.01,{ }^{* * *} p<0.001$ vs the CLP group. 

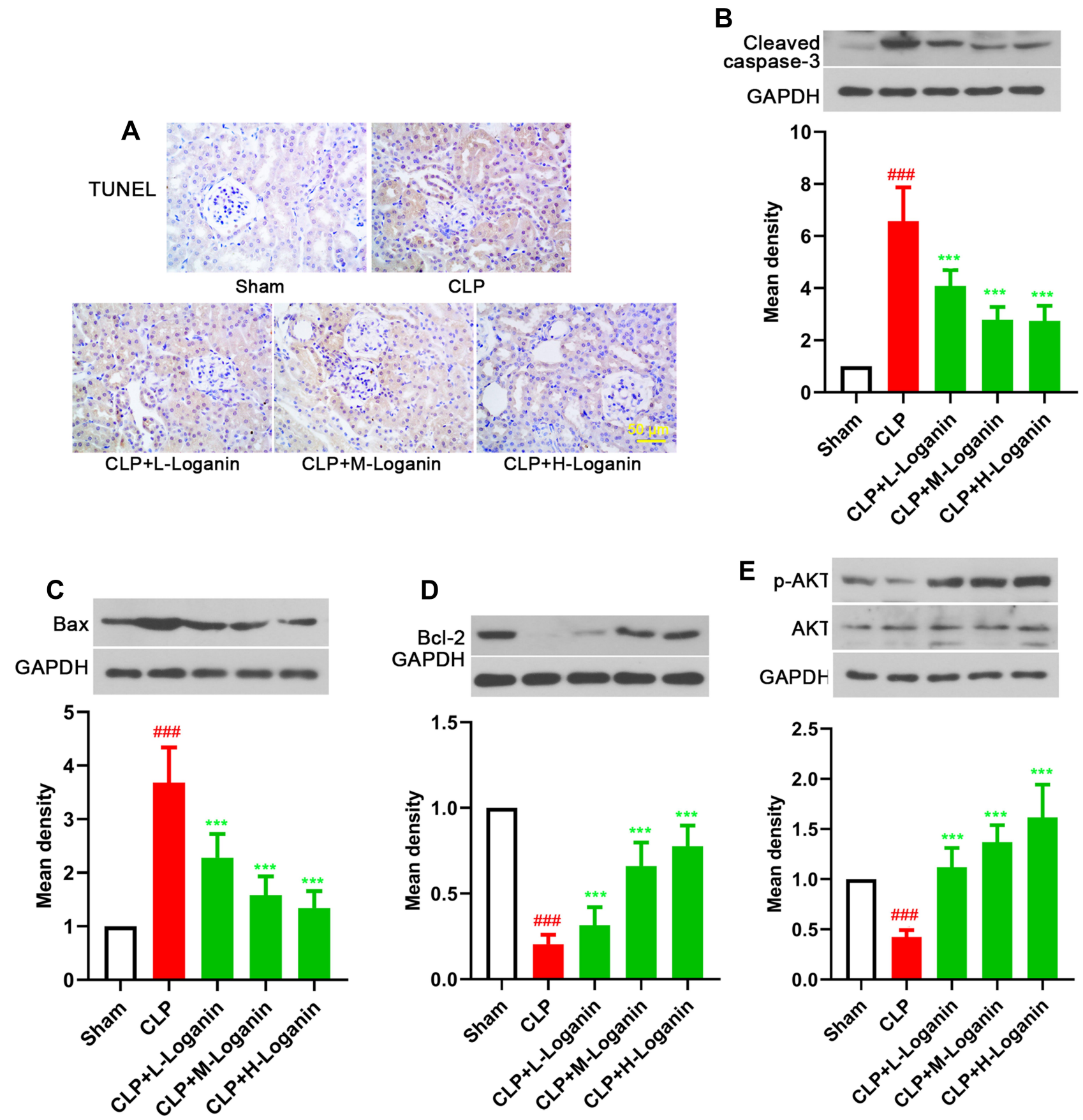

Figure 3 Effects of Loganin on apoptosis in kidney tissue of septic mice. (A) TUNEL staining in kidney tissue of septic mice. Representative Western blot for (B) cleaved caspase-3, (C) Bax, (D) Bcl-2 and (E) P-AKT in kidney tissue of septic mice after Loganin treatment. Data were represented as mean \pm SD at least six independent experiments and analyzed by one-way analysis of variance (ANOVA) followed by Tukey's multiple comparison test. ${ }^{\# \#} \mathrm{p}<0.00$ I vs the sham group and $* * * \mathrm{p}<0.00 \mathrm{I}$ vs the CLP group.

with the control $(\mathrm{p}<0.05)$, which could be lessened by Loganin incubation $(5,10,20 \mu \mathrm{M}, \mathrm{p}<0.05)$. The incubation of Loganin inhibited caspase-3 splitting and Bax expression, whereas elevated Bcl-2 levels in LPSstimulated HK2 cells (Figure 5B-D, 5, 10, $20 \mu \mathrm{M}, \mathrm{p}<$ $0.05)$. In addition, the aberrant phosphorylation of AKT was also reversed by Loganin treatment in LPSstimulated HK2 cells (Figure 5E, $20 \mu \mathrm{M}, \mathrm{p}<0.05$ ), which was consistent with the results of in vivo experiments, indicating Loganin inhibited LPS-induced HK2 cell apoptosis potentially by regulating AKT signaling pathway. 

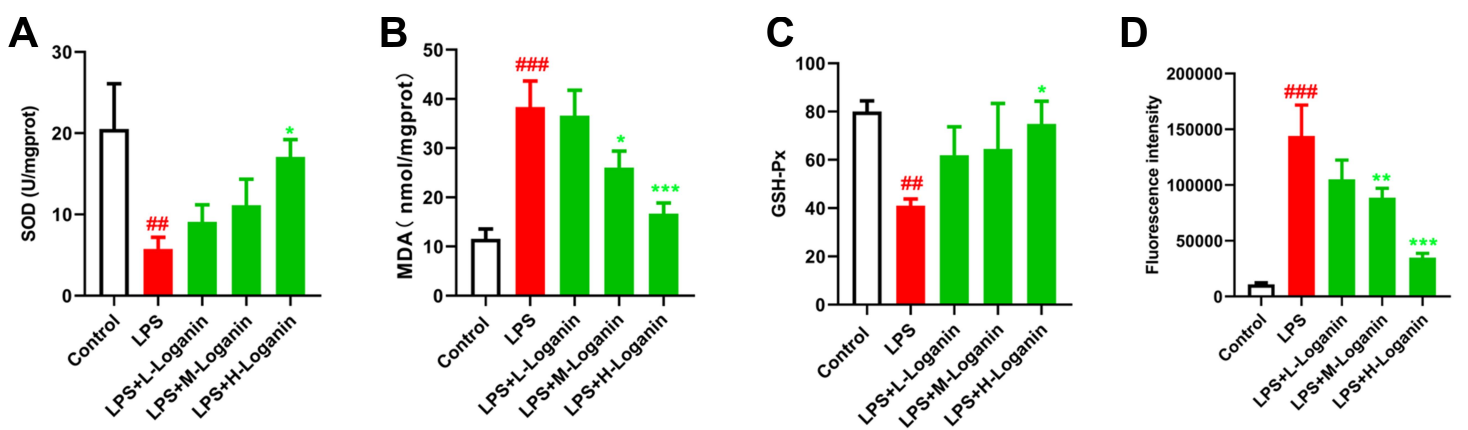
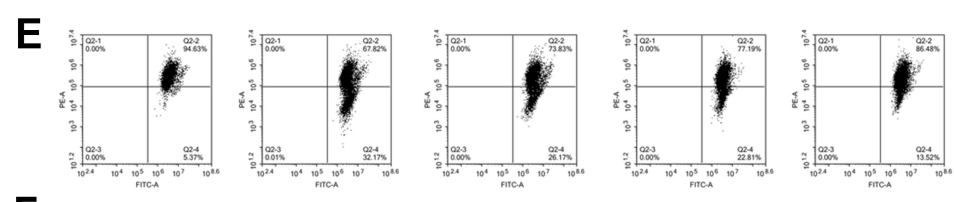

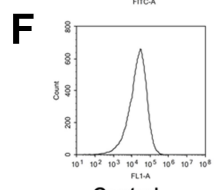

Control

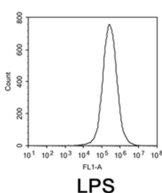

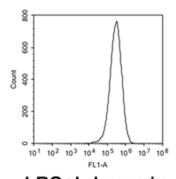

LPS+L-Loganin

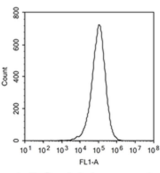

LPS+M-Loganin

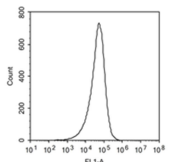

LPS+H-Loganin
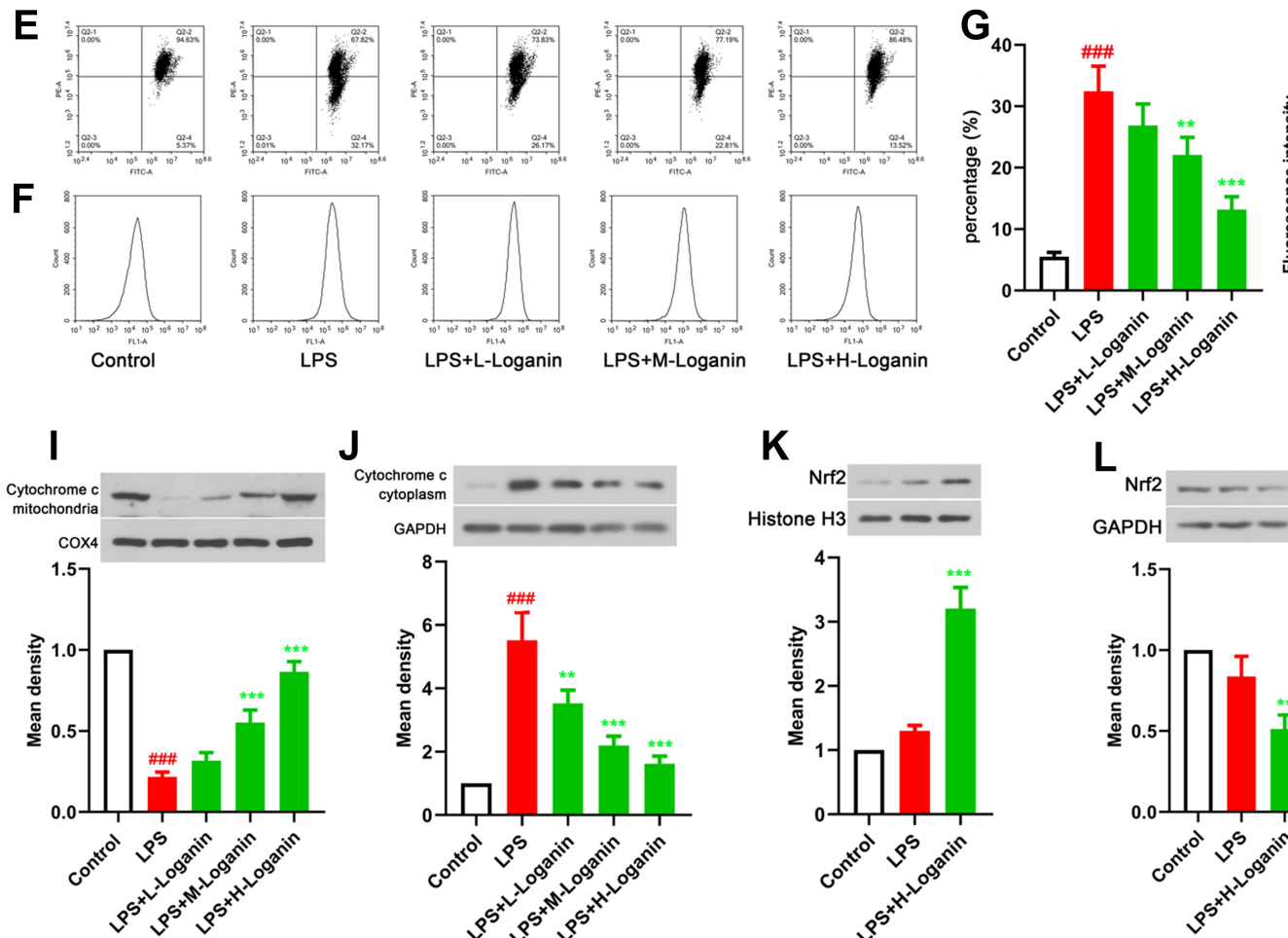

J

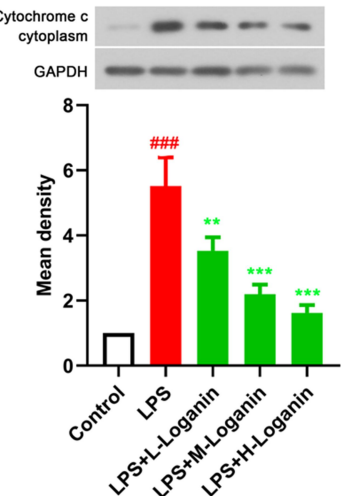

K

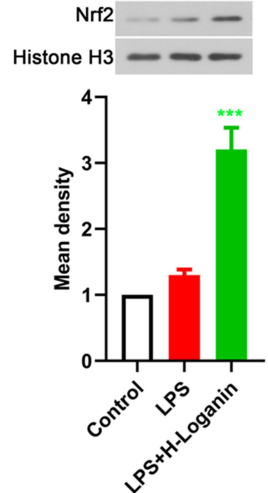

H

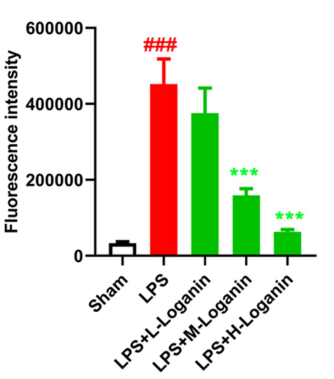

M

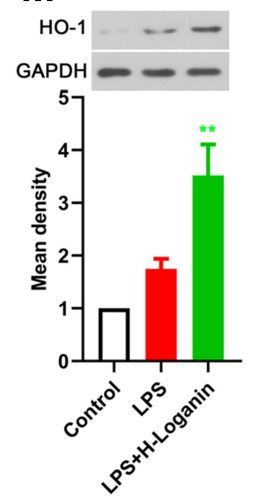

Figure 4 Effects of Loganin on oxidative stress and mitochondrial function in LPS-treated HK2 cells. (A) SOD activity in LPS-stimulated HK2 cells after Loganin treatment. (B) MDA levels in LPS-stimulated HK2 cells after Loganin treatment. (C) GSH-Px activity in LPS-stimulated HK2 cells after Loganin treatment. (D) ROS production in LPSstimulated HK2 cells after Loganin treatment. (E) and (G) Flow cytometry was used to analyze JC-I staining in LPS-stimulated HK2 cells after Loganin treatment. (F) and (H) Flow cytometry was used to analyze calcium overload in LPS-stimulated HK2 cells after Loganin treatment. Representative Western blot for (I) mitochondrial cytochrome c, (J) cytoplasmic cytochrome c, (K) nuclear Nrf2, (L) cytoplasmic Nrf2 and (M) HO-I in LPS-stimulated HK2 cells after Loganin treatment. Data were represented as mean \pm $\mathrm{SD}$ at least three independent experiments and analyzed by one-way analysis of variance (ANOVA) followed by Tukey's multiple comparison test. ${ }^{\prime} \mathrm{P}<0.0 \mathrm{I}$, ${ }^{\ldots} \mathrm{P}<0.00 \mathrm{I}$ vs the control group and $*_{p}<0.05 * * p<0.01$, $*^{* *} p<0.001$ vs the LPS group.

\section{Verifying the Effects of Loganin on Nrf2/ $\mathrm{HO}-\mathrm{I}$ and AKT Signaling Pathway}

The aforementioned data suggested both $\mathrm{Nrf} / \mathrm{HO}-1$ and AKT pathway might involve in the protective effects of Loganin on septic AKI. Finally, antagonist targeting the activity of Nrf2 and AKT, ML385 and LY294002 was used to verify the regulating effects of Loganin on Nrf2/ HO-1 and AKT signaling pathway in LPS-induced HK2 cells. As shown in Figure 6A-D, the antioxidant properties of Loganin were diminished by ML385 or LY294002 application in LPS-treated HK2 cells as indicated by SOD and GSH-Px activities as well as MDA and ROS productions $(\mathrm{p}<0.05)$. Besides, the protective effects of mitochondrial function of Loganin were offset by Nrf2 or AKT suppression (Figure 6E-H and $\mathrm{J}, \mathrm{p}<0.05$ ). Similarly, as indicated by flow cytometry results, its antiapoptotic effects were also weakened by ML385 or LY294002 (Figure 6I, p < 0.05). The above results proved that the protective effects of Loganin were mediated by regulating $\mathrm{Nrf} 2 / \mathrm{HO}-1$ and AKT signaling pathway, but the direct target of Loganin was left to be explored in the future. 
A

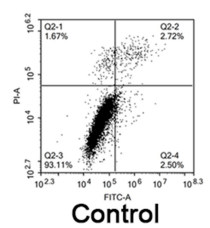

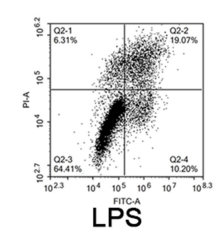
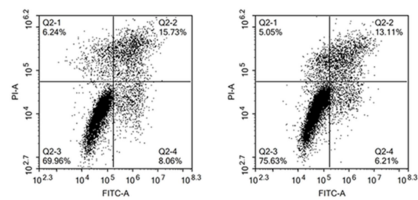

LPS+L-Loganin LPS+M-Loganin

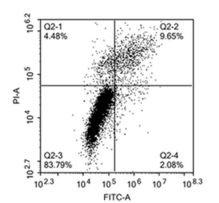

LPS $+\mathrm{H}-$ Loganin

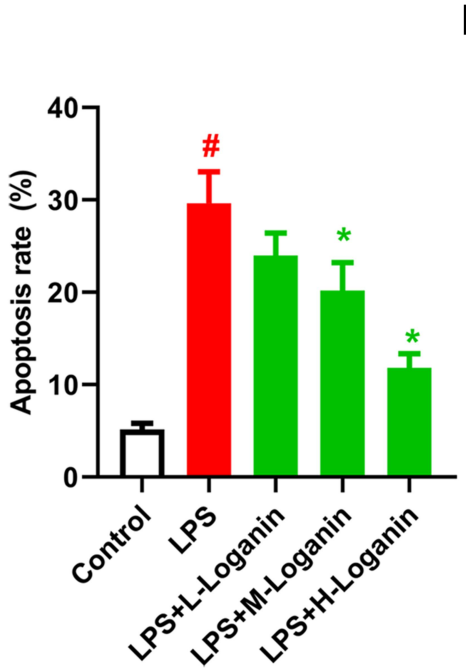

B

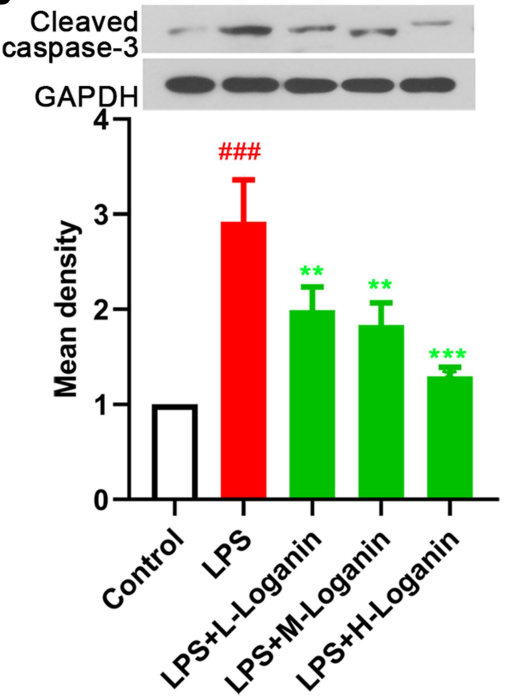

C

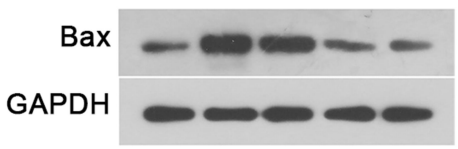

D
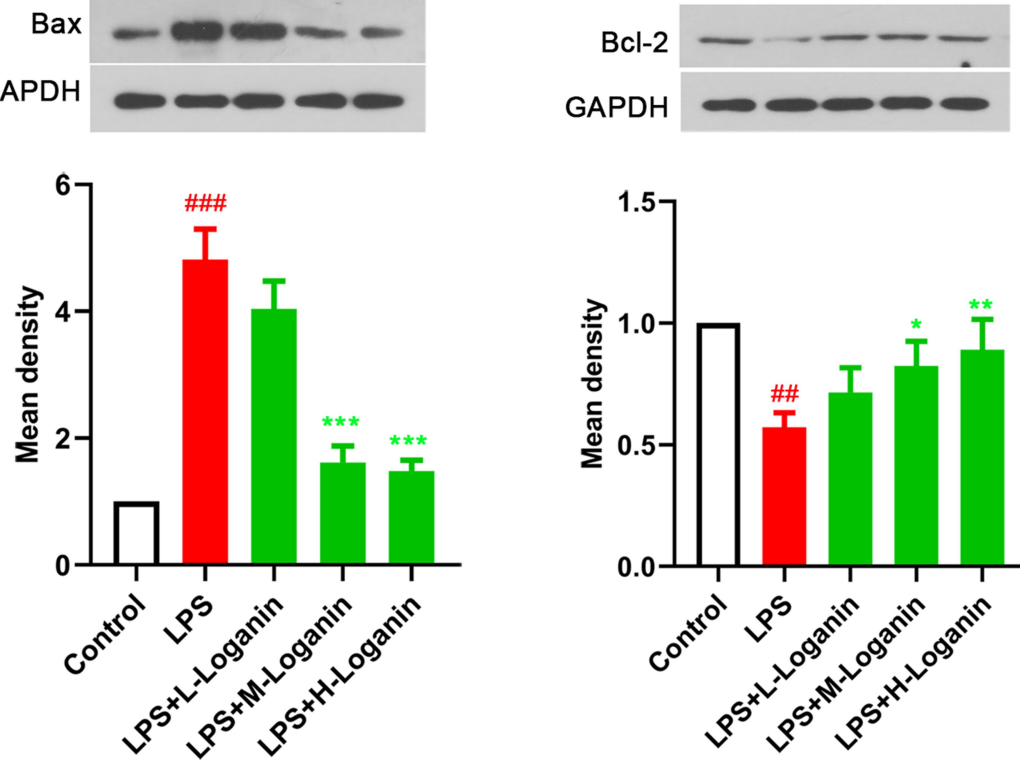

GAPDH

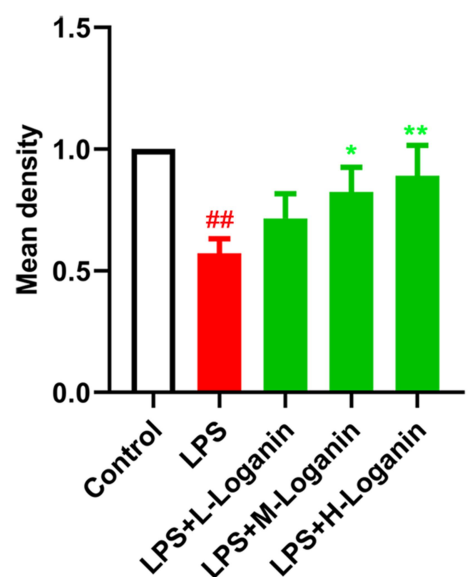

$E$
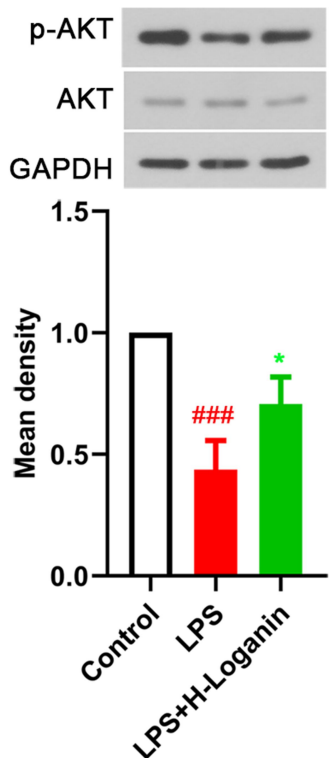

Figure 5 Effects of Loganin on apoptosis in LPS-treated HK2 cells. (A) Flow cytometry was used to analyze apoptosis in LPS-stimulated HK2 cells after Loganin treatment. Representative Western blot for (B) cleaved caspase-3, (C) Bax, (D) Bcl-2 and (E) P-AKT in LPS-stimulated HK2 cells after Loganin treatment. Data were represented as mean \pm SD at least three independent experiments and analyzed by one-way analysis of variance (ANOVA) followed by Tukey's multiple comparison test. ${ }^{\mathrm{P}}<0.05$, ${ }^{\#} \mathrm{P}<$ $0.01, \ldots+0.001$ vs the control group and ${ }^{*} \mathrm{p}<0.05{ }^{*} \mathrm{p}<0.01$, *** $\mathrm{p}<0.001$ vs the LPS group.

\section{Discussion}

Sepsis is a complex inflammatory condition that responded to infection. The complications of sepsis are varied. Acute lung injury (ALI) is the first to appear, whereas AKI is the most serious one resulting in a mortality of $45-70 \%$ in septic patients. ${ }^{10}$ In the present work, we aimed to study whether Loganin possessed the nephroprotective effect in septic mice and investigated the underlying mechanisms. Firstly, we found Loganin administration improved the survival rate in septic mice. Meanwhile, AKI was also relieved Loganin administration reflected by reduced oxidative stress, restored mitochondrial function, and inhibited apoptosis in the kidney tissue of septic mice. Besides, Loganin treatment promoted Nrf2 nuclear translocation, activated its downstream molecules, and simultaneously facilitated AKT phosphorylation in the kidney of septic mice and LPS-treated HK2 cells. Meanwhile, the beneficial effects of Loganin could be crippled by Nrf2 antagonist ML385 or PI3K inhibitor LY294002, indicating Nrf2/HO-1 and AKT signaling pathway activation is essential for the nephroprotective effects of 

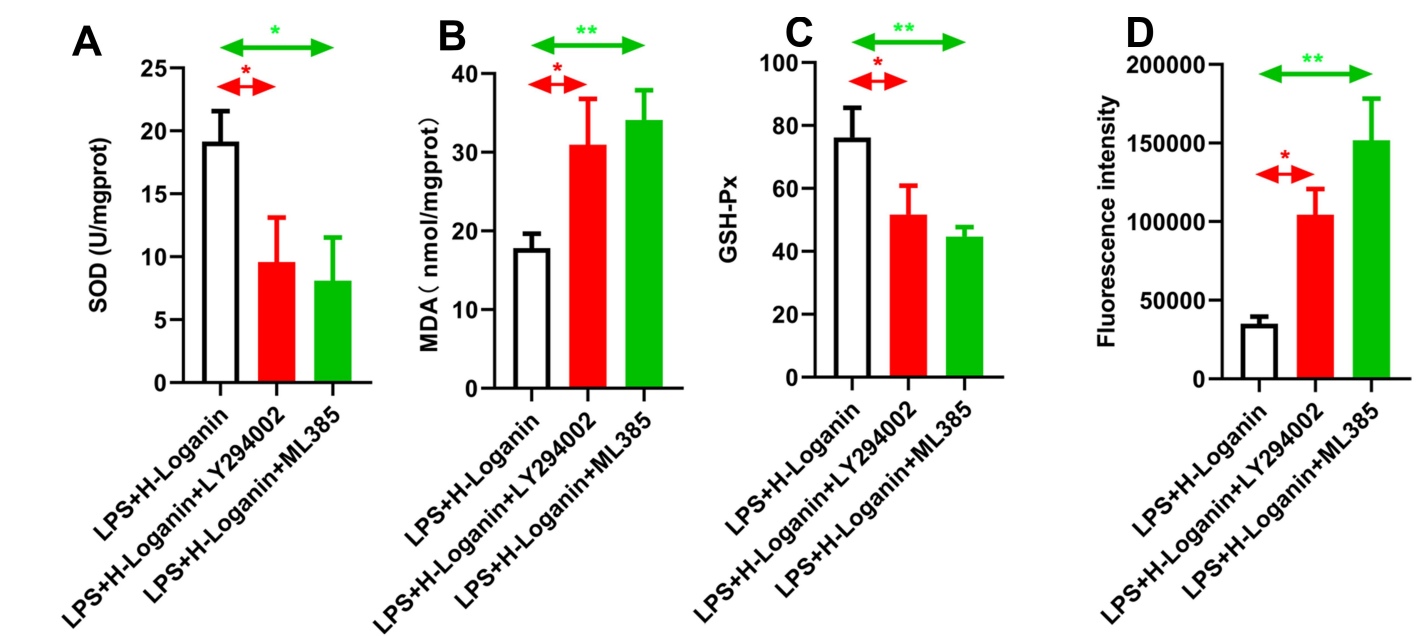

E

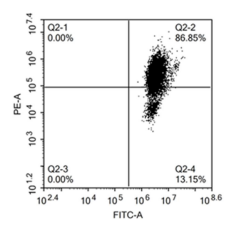

F

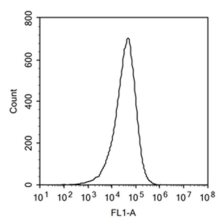

LPS+H-Loganin
I

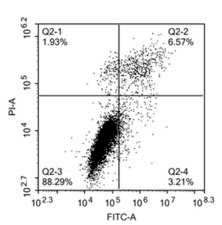

LPS $+\mathrm{H}$-Loganin

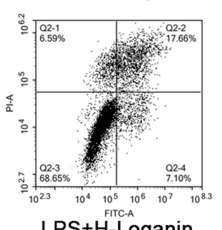

LPS $+\mathrm{H}-$ Loganin

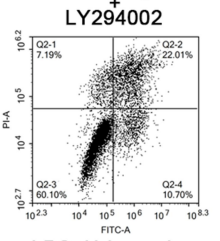

LPS+H-Loganin

ML385
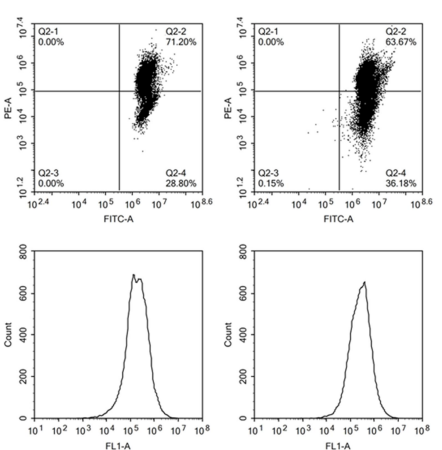

LPS+H-Loganin

LY294002

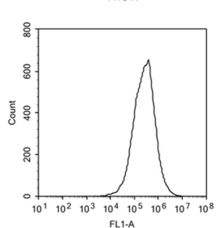

LPS+H-Loganin

ML385
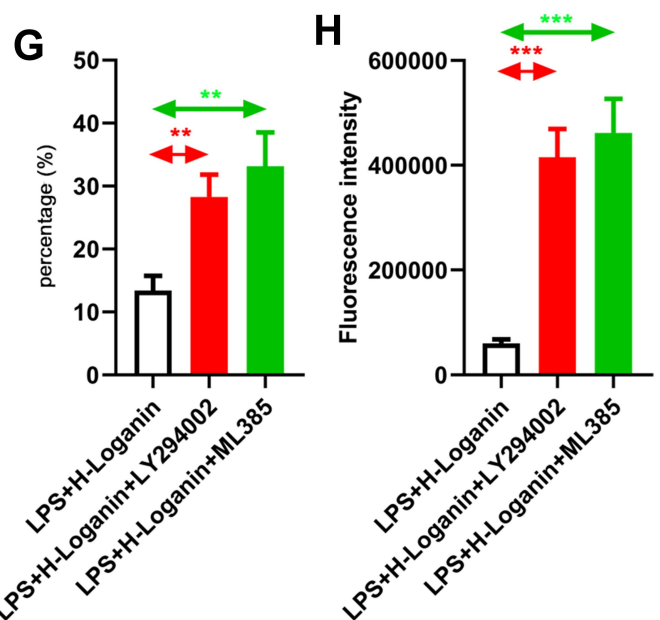

J
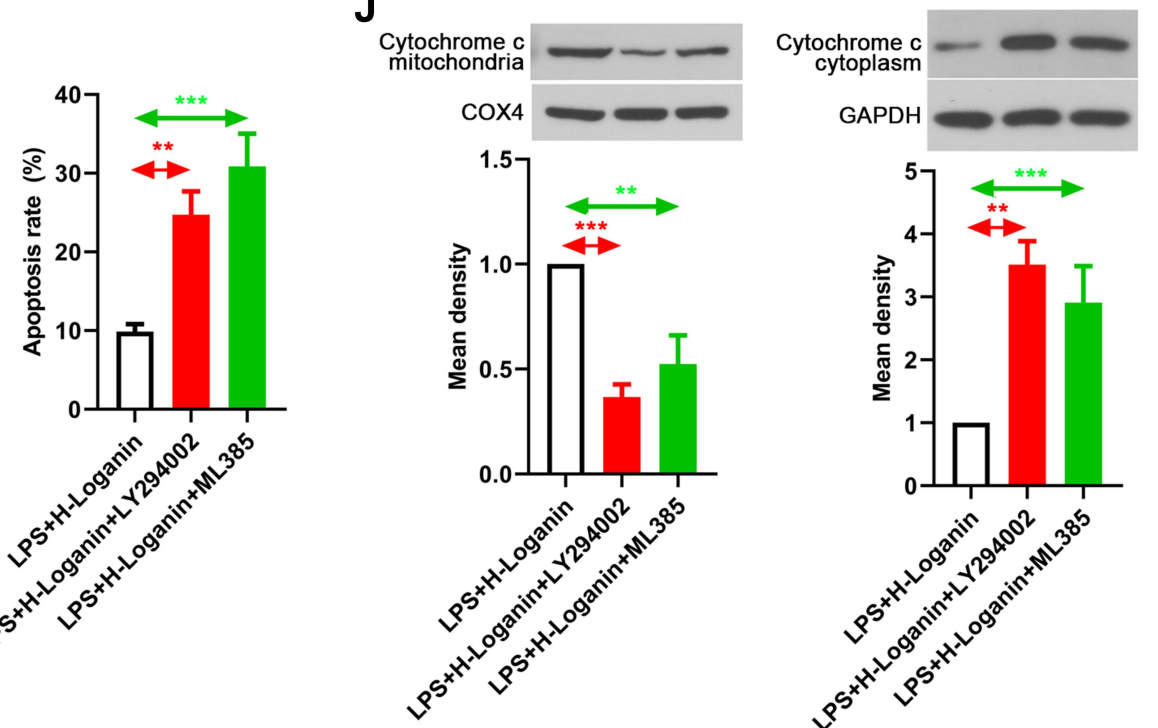

Figure 6 Verifying the effects of Loganin on AKT and Nrf2/HO-I signaling. (A) SOD activity in LPS-stimulated HK2 cells after Loganin treatment. (B) MDA levels in LPSstimulated HK2 cells after Loganin treatment. (C) GSH-Px activity in LPS-stimulated HK2 cells after Loganin treatment. (D) ROS production in LPS-stimulated HK2 cells after Loganin treatment. (E) and (G) Flow cytometry was used to analyze JC-I staining in LPS-stimulated HK2 cells after Loganin treatment. (F) and (H) Flow cytometry was used to analyze calcium overload in LPS-stimulated HK2 cells after Loganin treatment. (I) Flow cytometry was used to analyze apoptosis in LPS-stimulated HK2 cells after Loganin treatment. Representative Western blot for (J) mitochondrial cytochrome c and cytoplasmic cytochrome c in LPS-stimulated HK2 cells after Loganin treatment. Data were represented as mean \pm SD at least three independent experiments and analyzed by one-way analysis of variance (ANOVA) followed by Tukey's multiple comparison test. $*_{p}<0.05 * * p<0.01$, $* * * p<0.001$ vs the indicated group. 
Loganin in septic models. Above all, the present work suggested that Loganin treatment acquired protective effects in septic AKI through reducing oxidative stress and apoptosis via regulating $\mathrm{Nrf} / \mathrm{HO}-1$ and AKT signaling pathway.

The sepsis model was established by using the CLP method, which was supposed to be the gold in vivo model for the experimental sepsis. ${ }^{31}$ It is well accepted that CLP method can simulate clinical symptoms of sepsis more practically than endotoxin or bacteria injection method. ${ }^{32}$ Hence, CLP method was adopted in our work to evaluate the therapeutic effect of Loganin on septic AKI and its underlying mechanisms. In the present study, the degree of kidney injury was analyzed after CLP procedure in mice. Consistent with previous research, ${ }^{33}$ we found the levels of serum creatinine, blood urea nitrogen, and AKI marker NGAL expression were significantly increased, indicating the septic AKI models were successfully imitated. As the exhibited results, the survival rate in septic mice with Loganin treatment was distinctly increased, indicating the potential protection of Loganin in sepsis. Afterwards, the reduction in serum creatinine concentration, blood urea nitrogen level, and renal NGAL expression was observed in septic mice with Loganin treatment, suggesting the palliative effects of Loganin on sepsis-related AKI. The in vivo data preliminarily confirmed the renal protective effects of Loganin in septic mice.

It is well understood that excessive oxidative stress is appeared to participate in the process of kidney injury resulting from multiple factors, including diabetes and sepsis. ${ }^{34,35}$ The influence of abnormal oxidative stress in the kidney tissue of CLP-treated mice should not be belittled. The previous studies have reported that Loganin possesses the ability to restore the balance of oxidative stress in diabetic nephropathy animal models by downregulating MDA level while up-regulating SOD activity. ${ }^{29}$ Besides, Loganin also could remit inflammatory reaction, oxidative stress, and apoptosis in the livers of type 2 diabetic $\mathrm{db} / \mathrm{db}$ mice models. ${ }^{28}$ Based on these backgrounds, we preliminarily inferred that Loganin might play the protective role of renal injury in septic mice by alleviating oxidative stress and experiments were carried out. In our study, we found that the CLP procedure induced SOD and GSH-Px activity decline while MDA and ROS production rise in the kidney tissue, which could be restored by the single gavage of Loganin. Similar to previous studies, the results reminded that the anti-oxidant effect of Loganin might be the basis of its renal protection. $^{36,37}$ The evidence presented supported the strong relationship between mitochondrial dysfunction and abundant oxidative stress. ${ }^{38}$ In the work, we found the mitochondrial membrane potential loss and calcium overload were obvious in the kidney tissue after CLP procedure, indicating mitochondrial dysfunction occurred in the septic kidney. Not surprisingly, improved mitochondrial function reflected by elevated mitochondrial membrane potential and decreased calcium overload in the septic kidney was concurrently remitted by Loganin. The above results indicated that the anti-oxidation and mitochondrial function protection might be the basis for nephroprotective effects of Loganin.

Except for providing energy for cells, mitochondria are also involved in differentiation information transmission and apoptosis. ${ }^{39}$ Given that apoptosis, an important factor contributing to AKI progression, is worthy to be studied. Under the pathological conditions, cytochrome $\mathrm{c}$ in the inter-membrane space of mitochondria was released to cytoplasm, recruited apoptosome formation, and thereby inducing pathological apoptosis. ${ }^{40}$ Our data showed CLP surgery caused cytochrome c migration from mitochondrial inter-membrane space to the cytoplasm, which could be reversed by Loganin treatment. To evaluate apoptosis occurrence in the kidney, TUNEL staining and apoptosisrelated protein expressions (cleaved caspase-3, Bax, and Bcl-2) were detected. Fortunately, apoptosis could be inhibited by Loganin treatment in vivo and in vitro in a dose-dependent form, indicating the anti-apoptosis effects of Loganin.

Several lines of evidence showed that Nrf2 is a redoxsensitive transcription factor modulating the transcription of oxidative stress-associated genes. ${ }^{41}$ Meanwhile, the salutary effects of Loganin in type 2 diabetic $\mathrm{db} / \mathrm{db}$ might be mediated by Nrf2 introduction to the nuclei. ${ }^{28}$ Therefore, we speculated that Loganin might also alleviate septic AKI by activating Nrf2-related signalling pathway. Fortunately, we found that Loganin administration promoted Nrf2 nuclear translocation and HO-1 activation. Next, the in vitro studies were implemented to confirm whether Nrf2/HO-1 signaling was involved in the beneficial effect of Loganin in LPS-treated HK2 cells. Similar to the experimental results in vivo, Loganin alleviated oxidative stress injury, restored mitochondrial function, and inhibited apoptosis in LPSstimulated HK2 cells, which could be diminished by the specific Nrf2 inhibitor ML385. Although it has not been confirmed that $\mathrm{Nrf} 2$ is a direct target of Loganin, our experimental results show that $\mathrm{Nrf} 2 / \mathrm{HO}-1$ signaling 
pathway is closely related to its protective effect. The key point regulating apoptosis, AKT phosphorylation, was also measured in our work. Analogously, Loganin increased the phosphorylation of AKT in the injured kidney and LPS-stimulated HK2 cells. Besides, the salutary effects also diminished in vitro by LY294002, the broad-spectrum inhibitor of PI3K, indicating AKT pathway is associated with the property of Loganin. According to the validating results of in vitro experiments, our study suggested that Loganin alleviated septic AKI through regulating oxidative stress injury, mitochondrial function, and apoptosis in tubular epithelial cells, which might attribute to the involvement of AKT and Nrf2/HO-1 signaling. However, the direct target of Loganin remained to be explored, which was the focus of our future work.

Above all, our work suggested that Loganin possessed the property to remit AKI in septic mice by regulation of oxidative stress mitochondrial function and apoptosis tubular epithelial cells via AKT and Nrf2/HO-1 signaling, which might provide a new therapeutic strategy for septic AKI.

\section{Abbreviations}

AKI, acute kidney injury; CLP, cecal ligation and puncture; GSH-Px, glutathione peroxidase; LPS, lipopolysaccharides; HO-1, heme-oxygenase 1; Keap1, Kelch-like ECH associating protein 1; MDA, malonaldehyde; Nrf2, nuclear factor E2-related factor 2; ROS, reactive oxygen species; SOD, superoxide dismutase.

\section{Acknowledgment}

This research was supported by grants from the National Natural Science Foundation of China (No. 81571871 and 81770276) and Nn10 program of Harbin Medical University Cancer Hospital.

\section{Disclosure}

The authors declared no conflicts of interest for this work.

\section{References}

1. Christensen MG, Johnsen N, Skals M, et al. Prevention of P2 Receptor-Dependent Thrombocyte Activation by Pore-Forming Bacterial Toxins Improves Outcome in A Murine Model of Urosepsis. Int $J$ Mol Sci. 2020;21(16):5652. doi:10.3390/ ijms 21165652

2. Singer M, Deutschman CS, Seymour C, et al. The third international consensus definitions for sepsis and septic shock (sepsis-3). JAMA. 2016;315:801-810. doi:10.1001/jama.2016.0287
3. Zou Z, Wang Q, Zhou M, et al. Protective effects of P2X7R antagonist in sepsis-induced acute lung injury in mice via regulation of circ_0001679 and circ_0001212 and downstream Pln, Cdh2, and Npri3 expression. J Gene Med. 2020;11:e3261.

4. Navegantes-Lima KC, Monteiro VVS, de França Gaspar SL, et al. Agaricus brasiliensis Mushroom Protects Against Sepsis by Alleviating Oxidative and Inflammatory Response. Front Immunol. 2020;11:1238.

5. Li Y, Zhai P, Zheng Y, Zhang J, Kellum JA, Peng Z. Csf2 Attenuated Sepsis-Induced Acute Kidney Injury by Promoting Alternative Macrophage Transition. Front Immunol. 2020;11:1415.

6. World Health Organization, WHO Sepsis Technical Expert Meeting, Who. 2018 1-36. https://www.who.int/servicedeliverysafety/areas/ sepsis meeting2018/en/. Accessed January 19, 2021.

7. Nwafor D, Brown C. A novel role for tissue-nonspecific alkaline phosphatase at the blood-brain barrier during sepsis. Neural Regen Res. 2021;16:99.

8. Bagshaw SM, Lapinsky S, Dial S, et al. Acute kidney injury in septic shock: clinical outcomes and impact of duration of hypotension prior to initiation of antimicrobial therapy. Intensive Care Med. 2009;35:871-881.

9. Shigehiko U, John K, Rinaldo B, et al. Acute renal failure in critically ill patients, a multinational, multicenter study. JAMA. 2010;130:158-161.

10. Bagshaw SM, Laupland KB, Doig CJ, et al. Prognosis for long-term survival and renal recovery in critically ill patients with severe acute renal failure: a population-based study. Crit Care. 2005;9(6):R700-9. doi:10.1186/cc3879

11. Bonventre JV, Yang L. Cellular pathophysiology of ischemic acute kidney injury. J Clin Invest. 2011;121(11):4210-4221. doi:10.1172/ JCI45161

12. Opatrilova R, Kubatka P, Caprnda $M$, et al. Nitric oxide in the pathophysiology of retinopathy: evidences from preclinical and clinical researches. Acta Ophthalmol. 2018;96(3):222-231. doi:10.1111/ aos. 13384

13. Fei L, Jingyuan X, Fangte L, et al. Preconditioning with rHMGB1 ameliorates lung ischemia-reperfusion injury by inhibiting alveolar macrophage pyroptosis via the Keap1/Nrf2/HO-1 signaling pathway. $J$ Transl Med. 2020;18(1):301. doi:10.1186/s12967-020-02467-w

14. Garrido-Pascual P, Alonso-Varona A, Castro B, Burón M, Palomares T. H2O2-preconditioned human adipose-derived stem cells (HC016) increase their resistance to oxidative stress by overexpressing Nrf2 and bioenergetic adaptation. Stem Cell Res Ther. 2020;11(1):335. doi:10.1186/s13287-020-01851-Z

15. Yifan Z, Benxiang N, Zheng X, et al. Ceftriaxone Calcium Crystals Induce Acute Kidney Injury by NLRP3-Mediated Inflammation and Oxidative Stress Injury. Oxid Med Cell Longev. 2020;2020:6428498. doi: $10.1155 / 2020 / 6428498$

16. Luo J, Li X, Li X, et al. Selenium-Rich Yeast protects against aluminum-induced peroxidation of lipide and inflammation in mice liver. BioMetals. 2018;31(6):1051-1059. doi:10.1007/s10534-0180150-2

17. Diao C, Chen Z, Qiu T, et al. Inhibition of PRMT5 Attenuates Oxidative Stress-Induced Pyroptosis via Activation of the Nrf2/ HO-1 Signal Pathway in a Mouse Model of Renal Ischemia-Reperfusion Injury. Oxid Med Cell Longev. 2019;2019:2345658. doi:10.1155/2019/2345658

18. Kensler TW, Wakabayashi N, Biswal S. Cell survival responses to environmental stresses via the Keap1-Nrf2-ARE pathway. Annu Rev Pharmacol Toxicol. 2007;47:89-116. doi:10.1146/annurev. pharmtox.46.120604.141046

19. Zhou X, Liu Z, Ying K, et al. WJ-39, an Aldose Reductase Inhibitor, Ameliorates Renal Lesions in Diabetic Nephropathy by Activating Nrf2 Signaling. Oxid Med Cell Longev. 2020;2020:7950457. doi:10.1155/2020/7950457

20. Irazabal MV, Torres VE. Reactive Oxygen Species and Redox Signaling in Chronic Kidney Disease. Cells. 2020;9(6):1342. doi:10.3390/cells9061342 
21. Zhang X, Zhu Y, Zhou Y, Fei B. Activation of Nrf2 Signaling by Apelin Attenuates Renal Ischemia Reperfusion Injury in Diabetic Rats. Diabetes Metab Syn Obesity. 2020;13:2169-2177. doi:10.2147/DMSO.S246743

22. Ott M, Gogvadze V, Orrenius S, Zhivotovsky B. Mitochondria, oxidative stress and cell death. Apoptosis. 2007;12(5):913-922. doi:10.1007/s10495-007-0756-2

23. Dodd-O JM, Welsh LE, Salazar JD, et al. Effect of NADPH oxidase inhibition on cardiopulmonary bypass-induced lung injury. $\mathrm{Am}$ J Physiol. 2004;287(2):H927-36.

24. Ruffolo SC, Breckenridge DG, Nguyen M, et al. BID-dependent and BID-independent pathways for BAX insertion into mitochondria. Cell Death Differ. 2000;7(11):1101-1108. doi:10.1038/sj. cdd. 4400739

25. Lee KY, Sung SH, Kim SH, Jang YP, Oh TH, Kim YC. Cognitiveenhancing activity of loganin isolated from Cornus officinalis in scopolamine-induced amnesic mice. Arch Pharm Res. 2009;32 (5):677-683. doi:10.1007/s12272-009-1505-6

26. Shi R, Han Y, Yan Y, et al. Loganin exerts sedative and hypnotic effects via modulation of the serotonergic system and GABAergic neurons. Fron Pharmacol. 2019;10:409. doi:10.3389/ fphar.2019.00409

27. Li Y, Li Z, Shi L, et al. Loganin inhibits the inflammatory response in mouse 3T3L1 adipocytes and mouse model. Int Immunopharmacol. 2016;36:173-179. doi:10.1016/j.intimp.2016.04.026

28. Park $\mathrm{CH}$, Tanaka T, Kim JH, et al. Hepato-protective effects of loganin, iridoid glycoside from Corni Fructus, against hyperglycemia-activated signaling pathway in liver of type 2 diabetic $\mathrm{db} / \mathrm{db}$ mice. Toxicology. 2011;290(1):14-21. doi:10.1016/j. tox.2011.08.004

29. Liu K, Xu H, Lv G, et al. Loganin attenuates diabetic nephropathy in C57BL/6J mice with diabetes induced by streptozotocin and fed with diets containing high level of advanced glycation end products. Life Sci. 2015;123:78-85. doi:10.1016/j.lfs.2014.12.028

30. Kim H, Youn K, Ahn M-R, et al. Neuroprotective effect of loganin against $\mathrm{A} \beta 25-35$-induced injury via the NF- $\mathrm{KB}$-dependent signaling pathway in PC12 cells. Food Funct. 2015;6(4):1108-1116. doi:10.1039/C5FO00055F

31. Dejager L, Pinheiro I, Dejonckheere E, Libert C. Cecal ligation and puncture: the gold standard model for polymicrobial sepsis? Trends Microbiol. 2011;19(4):198-208. doi:10.1016/j.tim.2011.01.001
32. Doi K, Leelahavanichkul A, Yuen PST, Star RA. Animal models of sepsis and sepsis-induced kidney injury. J Clin Invest. 2009;119 (10):2868-2878. doi:10.1172/JCI39421

33. Sung P-H, Lo Chang C, Tsai T-H, et al. Apoptotic adipose-derived mesenchymal stem cell therapy protects against lung and kidney injury in sepsis syndrome caused by cecal ligation puncture in rats. Stem Cell Res Therapy. 2013;4(6):155. doi:10.1186/scrt385

34. Kim JY, Leem J, Hong HL. Protective effects of spa0355, a thiourea analogue, against lipopolysaccharide-induced acute kidney injury in mice. Antioxidants. 2020;9:1-13.

35. Chen X, Liu W, Xiao J, et al. FOXO3a accumulation and activation accelerate oxidative stress-induced podocyte injury. FASEB J. 2020;34(10):13300-13316. doi:10.1096/fj.202000783R.

36. Xia S, Lin H, Liu H, et al. Honokiol Attenuates Sepsis-Associated Acute Kidney Injury via the Inhibition of Oxidative Stress and Inflammation. Inflammation. 2019;42(3):826-834. doi:10.1007/ s10753-018-0937-x

37. Zhao H, Liu Z, Shen H, Jin S, Zhang S. Glycyrrhizic acid pretreatment prevents sepsis-induced acute kidney injury via suppressing inflammation, apoptosis and oxidative stress. Eur $J$ Pharm. 2019;2019:92-99. doi:10.1016/j.ejphar.2016.04.006

38. Ge M, Fontanesi F, Merscher S, Fornoni A. The Vicious Cycle of Renal Lipotoxicity and Mitochondrial Dysfunction. Front Physiol. 2020;11:732.

39. Clavier A, Rincheval-Arnold A, Colin J, Mignotte B, Guénal I. Apoptosis in Drosophila: which role for mitochondria? Apoptosis. 2016;21:239-251.

40. Liang S, Sun K, Wang Y, et al. Role of Cyt-C/caspases-9,3, Bax/ Bcl-2 and the FAS death receptor pathway in apoptosis induced by zinc oxide nanoparticles in human aortic endothelial cells and the protective effect by alpha-lipoic acid. Chem Biol Interact. 2016;258:40-51.

41. Feng X, Guan W, Zhao Y, et al. Dexmedetomidine ameliorates lipopolysaccharide-induced acute kidney injury in rats by inhibiting inflammation and oxidative stress via the GSK-3 $\beta / \mathrm{Nrf} 2$ signaling pathway. J Cell Physiol. 2019;234:18994-19009.
Drug Design, Development and Therapy

\section{Publish your work in this journal}

Drug Design, Development and Therapy is an international, peerreviewed open-access journal that spans the spectrum of drug design and development through to clinical applications. Clinical outcomes, patient safety, and programs for the development and effective, safe, and sustained use of medicines are a feature of the journal, which has also been accepted for indexing on PubMed Central. The manuscript management system is completely online and includes a very quick and fair peer-review system, which is all easy to use. Visit http://www. dovepress.com/testimonials.php to read real quotes from published authors. 